\title{
Utilization of poly(methyl methacrylate) - carbon nanotube and polystyrene - carbon nanotube in situ polymerized composites as masterbatches for melt mixing
}

\author{
M. Annala, M. Lahelin, J. Seppälä* \\ Aalto University School of Chemical Technology, Department of Biotechnology and Chemical Technology, Polymer \\ Technology Research Group, P.O. Box 16100, FI-00076 Aalto, Finland
}

Received 15 March 2012; accepted in revised form 6 May 2012

\begin{abstract}
Carbon nanotubes (CNTs) were melt mixed directly or by using an in situ polymerized masterbatch into a matrix polymer, polystyrene (PS) or poly(methyl methacrylate) (PMMA). The mechanical properties of the composites were mostly determined by the amount of CNTs, and not by the use of directly melt mixed CNTs or the use of the masterbatch. In contrast, the electrical resistivity of the composites was dependent on the manner in which the CNTs were added to the matrix polymer. When there was increased interfacial adhesion between the components, as for PS and the CNTs, the use of directly melt mixed CNTs gave better resistivity results. Without strong interactions between the CNTs and the matrix, as with PMMA and CNTs, the use of a tailored masterbatch had a significant effect on properties of the final composites. The molecular weight and viscosity of masterbatches can be varied and when the PMMA-masterbatch had optimized viscosity with respect to the PMMA matrix, electrical resistivity of the final composites decreased noticeably.
\end{abstract}

Keywords: polymer composites, nanocomposites, material testing, tailor-made polymers, carbon nanotubes

\section{Introduction}

Carbon nanotubes (CNTs) are unique materials with superior mechanical, thermal and electrical properties. CNTs are of increasing interest both in the academic and industrial worlds for use as fillers in polymer composites in which low mass, electrical conductivity and mechanical strength are required. In general, the challenge for controlling and predicting nanocomposite properties lies in understanding interfacial phenomena between the particles and polymers. The dispersion of the CNTs in the matrix polymer and interfacial adhesion between the CNTs and polymers are the two major factors that determine the reinforcement effect of the CNTs. Compromises have to be made in order to obtain high reinforcement and electrical conductivity in the resulting composite. The orientation of the CNTs in compos- ites has contradictory effects on the properties of the composite. Well-aligned CNTs in the composite improve mechanical properties $[1,2]$. Tensile toughness of poly(methyl methacrylate) (PMMA) increased $170 \%$ after addition of $1 \mathrm{wt} \% \mathrm{CNTs}$, which were oriented in the matrix [1]. On the other hand, electrical conductivity decreases in well-aligned CNTs [3-5]. In PMMA composites with $2 \mathrm{wt} \%$ CNTs, the nanotube alignment decreased the electrical conductivity from $10^{-4} \mathrm{~S} / \mathrm{cm}$ (unaligned) to $10^{-10} \mathrm{~S} / \mathrm{cm}$ (aligned) [4]. Electrical conductivity of the composites is based on the continuous network of the conductive phase throughout the composite. There are many factors to be considered when the conductivity of a composite is to be optimized. The CNTs are mainly concentrated in the amorphous phase of the matrix, and when the crystallinity of the matrix

\footnotetext{
${ }^{*}$ Corresponding author, e-mail: jukka.seppala@aalto.fi
}

(c) BME-PT 
increases, the concentration of the CNTs increases in the amorphous phase by increasing the conductivity of the composite [6].

CNTs, having high surface energy and strong van der Waals interactions, are difficult to disperse in the matrix polymer on the nanoscale level through simple mixing. Conventional mixing in solution or melt mixing usually gives nanoscale dispersion of CNTs with poor stability [7]. Yet direct melt mixing and the use of a masterbatch are highly desired processing methods in many applications which require highly stabile dispersions.

Direct melt mixing is not sufficient for breaking up CNT agglomerates and dispersing the CNTs into the matrix polymer when interfacial interactions are poor between the CNTs and the matrix polymer. Chemically modified CNTs are more soluble than pristine nanotubes and are more easily incorporated into a matrix polymer, including when using melt mixing. Using functionalized CNTs and a compatibilizer, Jin et al. [8] have managed to improve the dispersion of the CNTs in a polypropylene matrix in melt mixing. Lin et al. [9] have studied the mixing conditions in different melt mixers and the effect of shear on CNT agglomerates during mixing. Isayev et al. [10] have prepared an ultrasonic-assisted extruder for direct melt mixing, which enhanced the dispersion of the CNTs in polyetherimide. When composites are prepared by melt processing, the crystallinity of the matrix polymer affects both the mechanical properties and electrical conductivity of the composite. Coleman et al. [11] have determined that rather than acting as reinforcing agents, the major role played by the CNTs in improving the mechanical properties of composites is to nucleate polymer crystallization. The same phenomena have been observed with polypropylene-CNT composites $[6,12]$. In the case of the PP-CNT composite, the mechanical properties, elongation at break and impact strength, decreased as the amount of CNTs in the composite increased. With only a small amount of CNTs, $0.5 \mathrm{wt} \%$, the mechanical properties were improved, which was attributed to increased matrix crystallinity. Yet the percolation threshold was at $8.0 \mathrm{wt} \%$ CNTs [13]. In addition, a polyamide 6CNT composite was produced in which the crystallinity increased after addition of CNTs and mechanical properties were improved $[14,15]$.
To use a masterbatch, the CNTs are first dispersed in one polymer, and this composite is then melt blended with a second polymer. Melt mixing in extruders has provided a reasonably economical way to produce a wide range of polymer blends. The improvement in mechanical properties of a blend requires that the phase of the matrix polymer is continuous, and that there is sufficient adhesion between the phases. In melt mixing, phase separation can be controlled by adjusting the viscosity ratios [16] and shear rates [17] to achieve a morphology in which both phases are continuous or the CNT-rich polymer phase is continuous. In such blends, double percolation can be exploited to minimize the CNT content in the composite $[18,19]$. In polyamide 6-CNT composites, the percolation threshold was between 4-6 wt $\%$ CNTs. When this composite was blended with acrylonitrile/butadiene/ styrene (ABS), the CNTs were selectively located in the polyamide- 6 , and percolation threshold decreased to 2-3 wt $\%$ CNTs [18]. Depending on the conditions, the CNTs can reorganize during melt mixing by diffusion. The diffusivity of the CNTs is determined by the viscosity of the matrix polymer and thus the extent at which they can reorganize [20]. The thermodynamically-driven migration effect can be used to obtain well-dispersed CNTs in a matrix polymer. Pötschke et al. [21] have used a polyethylene-CNT masterbatch in extrusion with polycarbonate or polyamide. The CNTs diffused into matrix polymers that had lower interfacial energies with the CNTs. Electrical percolation was achieved at a lower CNT content than that needed with direct incorporation of the CNTs.

To obtain only mechanical improvements, Yuan et al. [22] prepared a polystyrene-CNT masterbatch by using in situ polymerization of styrene to coat the CNTs with polystyrene, and the masterbatch was diluted with melt mixing. They managed to enhance impact strength $250 \%$ compared with pure PS by adding $0.3 \mathrm{wt} \%$ CNTs to the composite, while maintaining the good dispersion of the CNTs. Tong et al. [23] coated the CNTs with polyethylene and after melt mixing with matrix polyethylene, the mechanical properties were similar to those of the matrix polymer; without coating the CNTs, poor mechanical properties obtained.

In this paper, we demonstrate the benefit of using the in situ polymerized composites as a master- 
batch. We have previously used in situ polymerization to form stable dispersions of CNTs in two different types of polymers, polystyrene and poly (methyl methacrylate) [24]. The properties of the in situ polymerized masterbatch can be tailored based on the desired viscosity to form conductive paths in the final composites. The viscosity of a masterbatch can be optimized by changing the molecular weight of a masterbatch and/or by adding plasticizer. We show that the addition of a plasticizer is an easy way to alter the viscosity of materials. We studied the effect of CNTs, both type and amount of CNT, in in situ emulsion and combined emulsion/suspension polymerization of styrene and methyl methacrylate. Based on the results, the preparation method of masterbatches was selected in order to obtain high content of CNTs and appropriate molecular weight of the masterbatch. Significant improvements for lowering resistivity of PMMA-CNT composite was achieved by using in situ polymerized masterbatch.

\section{Materials and methods}

\subsection{Materials}

Monomers styrene ( $>99 \%$, Fluka, Steinheim, Germany) and methyl methacrylate (MMA, $>99 \%$, Fluka, Steinheim, Germany) were treated with aluminum oxide (Fluka, Steinheim, Germany) to remove inhibitor, initiators potassium peroxodisulfate (KPS, Fluka, Steinheim, Germany) and azobisisobutyronitrile (AIBN, Fluka, Switzerland), surfactant sodium dodecyl benzene sulfate (DBSA, Fluka), buffer sodium hydrogen carbonate $\left(\mathrm{NaHCO}_{3}\right.$, Merck), plasticizer glycerol ( $>99 \%$, Merck), and multi-walled carbon nanotubes (CNTs, NC7000, Nanocyl, Sambreville, Belgium) were used as received. CNTs has been manufactured via a chemical vapor deposition (CVD) process, the carbon purity is $\sim 90 \%$, average diameter $\sim 9.5 \mathrm{~nm}$, and average length $\sim 1.5 \mu \mathrm{m}$ according to manufacturer. All water used was distilled. Matrix polymers polystyrene (PS, Styron 678E, Styron Europe GmbH, Horgen, Switzerland) and poly(methyl methacrylate) (PMMA, IG840, LG Chemicals, Korea) were milled before melt mixing.

\subsection{In situ - polymerization of masterbatches}

The molecular weight of a polymer depends on the polymerization method and the amount of CNTs in the in situ polymerization reaction [24]. Therefore two polymerization techniques were used in order to control the molecular weights: emulsion polymerization with KPS as an initiator and combined emulsion/suspension polymerization with AIBN as an initiator. PMMA-masterbatch was prepared by using emulsion polymerization method with $10 \mathrm{wt} \%$ CNTs in order to get molecular weight that approaches the molecular weight of commercial PMMA matrix. High molecular weight PS-masterbatch was prepared by using the emulsion polymerization method with $12 \mathrm{wt} \%$ CNTs and low molecular weight PS-masterbatch by using combined emulsion/suspension method with $6 \mathrm{wt} \%$ CNTs.

At first, a seed emulsion was prepared. The CNTs, $0.5 \mathrm{~g}$ surfactant, $0.1 \mathrm{~g}$ buffer, and $90 / 100 \mathrm{~mL}$ water were introduced into a $250 \mathrm{~mL}$ three-neck round bottom flask, cooled in an ice bath, and the mixture was deoxygenated with argon. Ultrasonic irradiation was carried out with the probe of the ultrasonic horn immersed directly into the mixed system. The power output was set at $100 \mathrm{~W}$ and the system was irradiated $30 \mathrm{~min}$. After ultrasonic treatment, the flask was transferred into an oil bath and fitted with a stirrer under argon atmosphere.

In the case of the emulsion polymerization, $0.09 \mathrm{~g}$ initiator (KPS) was dissolved in $10 \mathrm{~mL}$ water and the solution was fed into the seed emulsion before monomer feed. The monomer $(5 \mathrm{~mL})$ was added dropwise with a membrane pump at $0.03 \mathrm{~mL} / \mathrm{min}$ to control the growing polymer particles in the emulsion. Polymerizations were conducted with a stirring rate of $300 \mathrm{rpm}$ under argon atmosphere for 15 $18 \mathrm{~h}$ at $60^{\circ} \mathrm{C}$ for PMMA-masterbatches and at $70^{\circ} \mathrm{C}$ for PS-masterbatches.

In the case of the combined emulsion/suspension polymerization, $0.045 \mathrm{~g}$ initiator (AIBN) was dissolved in $5 \mathrm{~mL}$ of styrene and the solution was fed into the seed emulsion with the membrane pump at $0.03 \mathrm{~mL} / \mathrm{min}$. Polymerization was conducted with stirring rate of $300 \mathrm{rpm}$ under argon atmosphere for $3 \mathrm{~h}$ at $80^{\circ} \mathrm{C}$.

The emulsions were dried at $50^{\circ} \mathrm{C}$ in an oven overnight. To adjust the viscosity of a masterbatch, a plasticizer (30 $\mathrm{wt} \%$ or $50 \mathrm{wt} \%$ based on monomer content) was added to the emulsion before drying. The masterbatches with added plasticizer are referred to as plast 30 and plast50, respectively. 


\subsection{Melt mixing}

The composites were prepared with a corotating twin-screw midiextruder (DSM, Pforzheim, Germany; capacity $=16 \mathrm{~cm}^{3}$; screw length $L=150 \mathrm{~mm}$ ) under nitrogen atmosphere. In the case of PS composites, different screw speeds, $60 / 80 / 120 \mathrm{rpm}$, and mixing times, $5 / 10 / 15 \mathrm{~min}$, were tested at $190^{\circ} \mathrm{C}$. PMMA composites were mixed at $120 \mathrm{rpm}$ for $10 \mathrm{~min}$ at $210^{\circ} \mathrm{C}$. The CNT content in composites was $1-4 \mathrm{wt} \%$ and the CNTs were incorporated directly or by using a masterbatch. The masterbatches were in powder form after drying. In order to obtain favorable phase morphology of the masterbatches in the final composite, matrix polymers were milled. The particle size of the masterbatch varied from fine powder to coarse powder, because some agglomeration of polymer pearls occurred during drying. Therefore matrix polymers were milled to a fine powder with particle size less than $500 \mu \mathrm{m}$. The components were mixed together before feeding into the midiextruder. The samples were designated based on the content of CNTs in the composite, followed by how CNTs were incorporated, directly (CNTs) or with masterbatch (MB), and the matrix polymer.

\subsection{Characterization}

Molecular weights $\left(M_{\mathrm{w}}\right)$ and molecular weight distributions (D) were determined with respect to polystyrene standards by size exclusion chromatography (SEC, The Waters Associates system, USA). The samples were dissolved in tetrahydrofuran (THF) and THF was used as eluent. The samples were analyzed at room temperature.

Mechanical properties of the composites were characterized from hot-pressed samples (hot-press, Fontijne TP 400, the Netherlands). The used melting and pressing temperatures and times were $170^{\circ} \mathrm{C} / 5 \mathrm{~min}$ for PS and $165^{\circ} \mathrm{C} / 4 \mathrm{~min}$ for PMMA. The used pressure was $150 \mathrm{kN}$. Tensile tests were performed with an Instron 4202 testing machine (Instron, United Kingdom) using a test speed of $5 \mathrm{~mm} / \mathrm{min}$ and with specimen type 1BA according to the standard ISO 527:1993(E).

The bulk resistivity of the composites was measured by the four-probe method (Keithley 2400 Sourcemeter, USA). Alligator clips were used as electrodes and the electrodes were placed in the middle of the tensile test specimen. The cross sectional area of the tensile test specimen was $0.075 \mathrm{~cm}^{2}$. The distance between the clips was $1 \mathrm{~mm}$. The measurement was repeated three times per sample and the electrical resistivity was determined as an average value.

Thermal analyses with differential scanning calorimetry (Mettler Toledo DSC 821, Switzerland) using a heating rate of $10^{\circ} \mathrm{C} / \mathrm{min}$ from $25^{\circ} \mathrm{C}$ to $190^{\circ} \mathrm{C}$ with PS and to $220^{\circ} \mathrm{C}$ with PMMA were carried out to determine the glass transition temperatures, $T_{\mathrm{g}}$.

The melt rheological properties of the masterbatches were determined indirectly from the final composites by using a rotation rheometer (Anton Paar Physica MCR 301, Austria) with parallel plate geometry, gap $0.4 \mathrm{~mm}$, at $190^{\circ} \mathrm{C}$ for PS and at $210^{\circ} \mathrm{C}$ for PMMA, using dynamic oscillation frequency sweeps of $0.1-100 \mathrm{rad} / \mathrm{s}$ under nitrogen atmosphere. The morphology of the composites was characterized with a field emission scanning electron microscope (SEM, JSM-6335F JEOL, Tokyo, Japan). The extrudates were fractured after cooling in liquid nitrogen, and the fractured surfaces were sputter-coated with platinum under argon. The electron micrographs were taken using an acceleration voltage of $5.0 \mathrm{kV}$.

\section{Results and discussion}

We have investigated a number of parameters that can affect the final properties of CNT composites. The purpose was to obtain a conductive composite, and the mechanical properties were determined for chosen samples based on their electrical performance. Two different polymers were chosen as matrix polymers. The first was polystyrene, which has a compatible structure with CNTs, and interactions were based on $\pi$-stacking. The latter was poly(methyl methacrylate), which does not have favorable groups in the backbone or the side chain to form strong interactions with CNTs. All properties, i.e. resistivity and mechanical properties, were analyzed from unoriented CNT composite samples.

There are only limited possibilities to affect shear forces in the midiextruder to disperse the CNTs into the matrix polymer. Therefore, the particle size of the matrix polymers was reduced by milling in order to improve the dispersion of CNTs in the final composites. The effect of various mixing times and rotation speeds on the dispersion of CNTs was studied with polystyrene, which have strong interactions 
Table 1. The electrical resistivity and mechanical properties of polystyrene samples; melt mixing parameters were 10 min and $120 \mathrm{rpm}$, if not marked otherwise

\begin{tabular}{|c|c|c|c|c|c|}
\hline Sample & $\begin{array}{c}\text { CNT content } \\
{[w t \%]}\end{array}$ & $\begin{array}{c}\text { Electrical resistivity } \\
{[\Omega \cdot \mathrm{cm}]}\end{array}$ & $\begin{array}{c}\text { Young's modulus } \\
\text { [MPa] }\end{array}$ & $\begin{array}{c}\text { Tensile strength } \\
\text { [MPa] }\end{array}$ & $\begin{array}{c}\text { Strain } \\
{[\%]}\end{array}$ \\
\hline PS & - & $10^{20}-10^{22}$ a) & $1170 \pm 43$ & $34 \pm 2$ & $3.3 \pm 0.2$ \\
\hline $1 \mathrm{CNTs} / \mathrm{PS}$ & 1 & $>10^{9}$ & $1130 \pm 24$ & $28 \pm 3$ & $2.8 \pm 0.3$ \\
\hline $1 \mathrm{MB}_{\mathrm{PS}, \mathrm{KPS}} / \mathrm{PS}$ & 1 & $>10^{9}$ & $1210 \pm 48$ & $31 \pm 4$ & $3.0 \pm 0.1$ \\
\hline $2 \mathrm{CNTs} / \mathrm{PS}$ & 2 & $1.1 \cdot 10^{5}$ & $1170 \pm 58$ & $20 \pm 8$ & $2.1 \pm 0.7$ \\
\hline $2 \mathrm{MB}_{\mathrm{PS}, \mathrm{KPS}} / \mathrm{PS}$ & 2 & $2.0 \cdot 10^{7}$ & $1290 \pm 71$ & $30 \pm 3$ & $2.8 \pm 0.4$ \\
\hline $2 \mathrm{MB}_{\mathrm{PS}, \mathrm{KPS}} / \mathrm{PS} 5 \mathrm{~min} / 120 \mathrm{rpm}$ & 2 & $>10^{9}$ & - & - & - \\
\hline $2 \mathrm{MB}_{\mathrm{PS}, \mathrm{KPS}} / \mathrm{PS} 5 \mathrm{~min} / 60 \mathrm{rpm}$ & 2 & $>10^{9}$ & - & - & - \\
\hline $2 \mathrm{MB}_{\mathrm{PS}, \mathrm{KPS}} / \mathrm{PS} 10 \mathrm{~min} / 60 \mathrm{rpm}$ & 2 & $>10^{9}$ & - & - & - \\
\hline $2 \mathrm{MB}_{\mathrm{PS}, \mathrm{AIBN}} / \mathrm{PS}$ & 2 & $2.6 \cdot 10^{7}$ & $1180 \pm 58$ & $22 \pm 10$ & $2.2 \pm 0.9$ \\
\hline $2 \mathrm{MB}_{\mathrm{PS}, \mathrm{AIBN}}$ plast30/PS & 2 & $1.1 \cdot 10^{5}$ & $990 \pm 30$ & $18 \pm 3$ & $2.2 \pm 0.5$ \\
\hline $3 \mathrm{CNTs} / \mathrm{PS}$ & 3 & 650 & $1170 \pm 53$ & $18 \pm 7$ & $1.8 \pm 0.4$ \\
\hline $4 \mathrm{CNTs} / \mathrm{PS}$ & 4 & 180 & $1220 \pm 26$ & $28 \pm 1$ & $2.5 \pm 0.1$ \\
\hline
\end{tabular}

a) The resistivity of pure PS is a literature value, from ref [25]

with the CNTs. Based on the conductivity of the composites, the most efficient combination of mixing time and rotation speed was $120 \mathrm{rpm}$ and $10 \mathrm{~min}$ (Table 1). This combination was the best for preparing both the directly melt mixed CNT composites and the masterbatch composites of polystyrene.

In general, the resistivity decreased when the CNT content increased in the composites. PS composites were conductive with CNT loading of $1-2 \mathrm{wt} \%$ (Table 1). Due to the compatible structure of the CNTs and polystyrene, CNTs disperse more easily into the PS matrix, and the directly melt mixed PSCNT composites were conductive with CNT loading of $1-2 \mathrm{wt} \%$. By using a masterbatch, the same conductivity level with the same CNT loading was achieved in the final composite. However, the properties of a masterbatch affected greatly to the conductivity of the final PS composite. When the masterbatch was used, the properties of the masterbatch were needed to optimize in order to achieve the conductive composite.

The molecular weight of matrix polymers affects the mechanical and rheological properties [25, 26]. Therefore, the molecular weights were analyzed by rheometry. Based on the rheological model of the volume fraction $(\phi)$ and viscosity $(\eta)$, phase continuity and inversion in polymer blends and simultaneous interpenetrating networks can be predicted (Equation (1)) [16]:

$\frac{\eta_{1}}{\eta_{2}}=\frac{\phi_{2}}{\phi_{1}} \cong 1$

The matrix polymers have quite low molecular weights compared to the masterbatches (Table 2).
Table 2. Molecular weights $\left(M_{\mathrm{w}}\right)$, molecular weight distributions (PD), and glass transition temperatures $\left(T_{\mathrm{g}}\right)$

\begin{tabular}{|c|c|c|c|c|}
\hline Sample & $\begin{array}{c}\text { CNT } \\
\text { content } \\
{[w t \%]}\end{array}$ & $\begin{array}{c}\mathbf{M}_{w} \\
{[\mathrm{~g} / \mathrm{mol}]}\end{array}$ & PD & $\begin{array}{c}\mathbf{T}_{\mathbf{g}} \\
{\left[{ }^{\circ} \mathbf{C}\right]}\end{array}$ \\
\hline PS, powder & - & 260000 & 2.5 & 87 \\
\hline $\mathrm{MB}_{\mathrm{PS}}(\mathrm{KPS})$ & 12 & 1450000 & 3.3 & 89 \\
\hline $\mathrm{MB}_{\mathrm{PS}}(\mathrm{AIBN})$ & 6 & 630000 & 3.4 & 107 \\
\hline $\mathrm{MB}_{\mathrm{PS}}(\mathrm{AIBN})$ plast30 & 6 & 630000 & 3.4 & 106 \\
\hline PMMA, powder & - & 93000 & 1.9 & 106 \\
\hline MB & 10 & 280000 & 3.8 & 123 \\
\hline MB $_{\text {PMMA }}$ plast30 & 10 & 280000 & 3.8 & 118 \\
\hline
\end{tabular}

The final PS composites with the high molecular weight PS-masterbatch were conductive below $3 \mathrm{wt} \%$ CNTs. However, directly melt mixed PSCNT composites were already conductive below 2 wt $\%$ CNTs.

The morphology of the composite is affected by the viscosity of the masterbatch, thus rheological measurements were carried out. The viscosities of masterbatches could not be measured directly due to instrument limitations, therefore the measurements were performed with the final composites. Indirect measurements of rheological properties of the materials revealed that the addition of CNTs increased the viscosity and dynamic moduli of the composites (Figures 1-2). The viscosity of the final PS composites was highest when the masterbatches were used, as the higher molecular weight of the polymer induces a higher viscosity (Figure 1).

The viscosity of the PS matrix increased after addition of CNTs (Figure 1). There was also a notable difference between the high molecular weight PSmasterbatch and the low molecular weight PS-mas- 

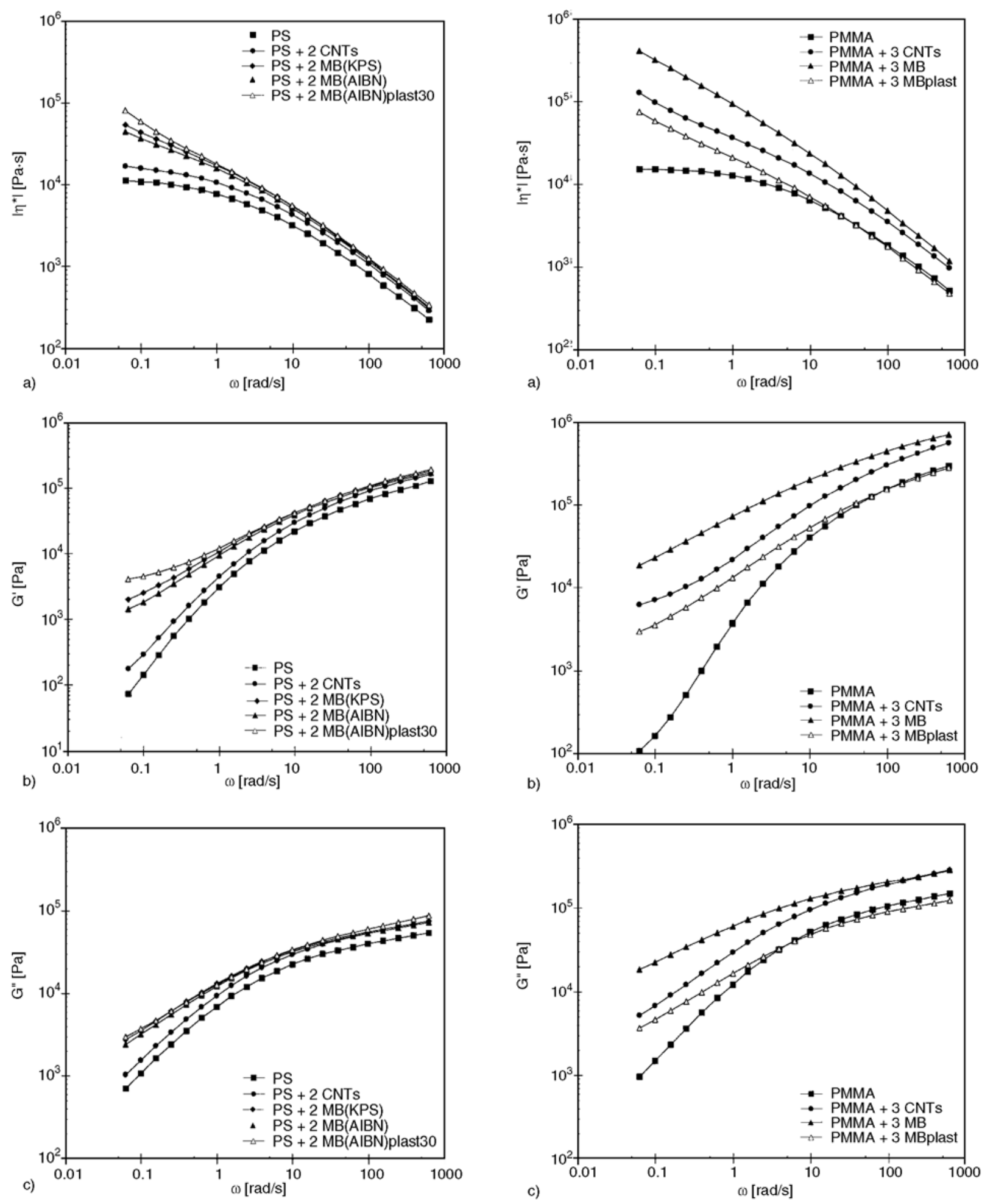

Figure 1. Complex viscosity (a), storage modulus (b), and loss modulus (c) of the final PS composites

terbatch. The difference was more pronounced at low frequency, where the viscosity of high molecular weight PS-masterbatch was higher than that of the lower molecular weight PS-masterbatch with the same amount of CNTs in the final composites.

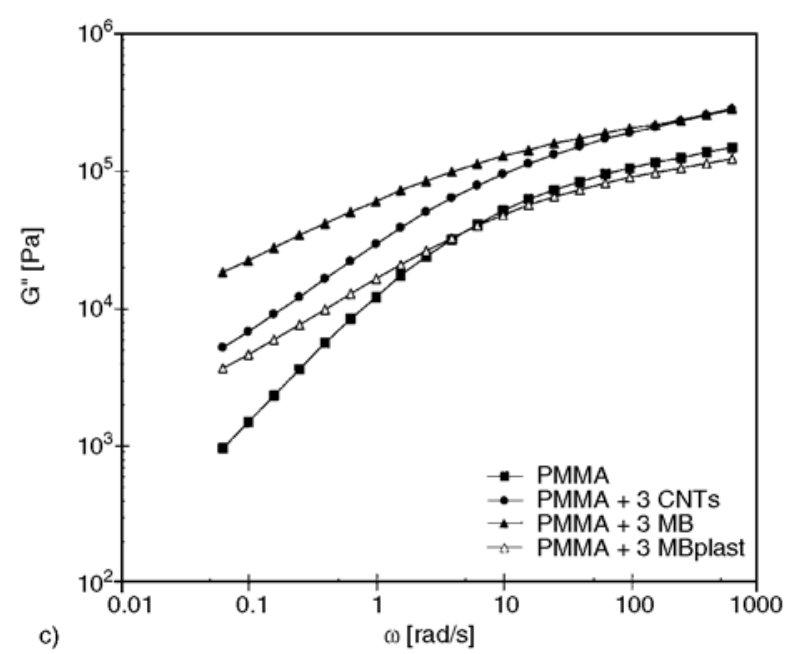

Figure 2. Complex viscosity (a), storage modulus (b), and loss modulus (c) of the final PMMA composites

The high molecular weight PS-masterbatch had the higher melt viscosity compared to the viscosity of the PS matrix. Based on the Equation 1, the masterbatch formed a discontinuous phase, because of the insufficient viscosity ratio of the components. In 
order to improve the viscosity ratio of the components, the molecular weight of the PS-masterbatch was decreased by changing the in situ polymerization method. When the molecular weight of the PSmasterbatch was decreased and with higher polydispersity, the viscosity of the masterbatch slightly decreased. However, the resistivity of the final PS composite with the low molecular weight masterbatch was not decreased compared to the final PS composite with high molecular weight masterbatch (Table 1).

In the final PS composite with the low molecular weight masterbatch, the CNTs remained primarily in the PS-masterbatch phase due to the presence of AIBN initiator. The initiator can form additional bonding with CNTs [27], and some polymer pearls were tightly attached to CNTs preventing them from diffusing to the matrix polymer from the masterbatch (Figure 3). Therefore, the lower molecular

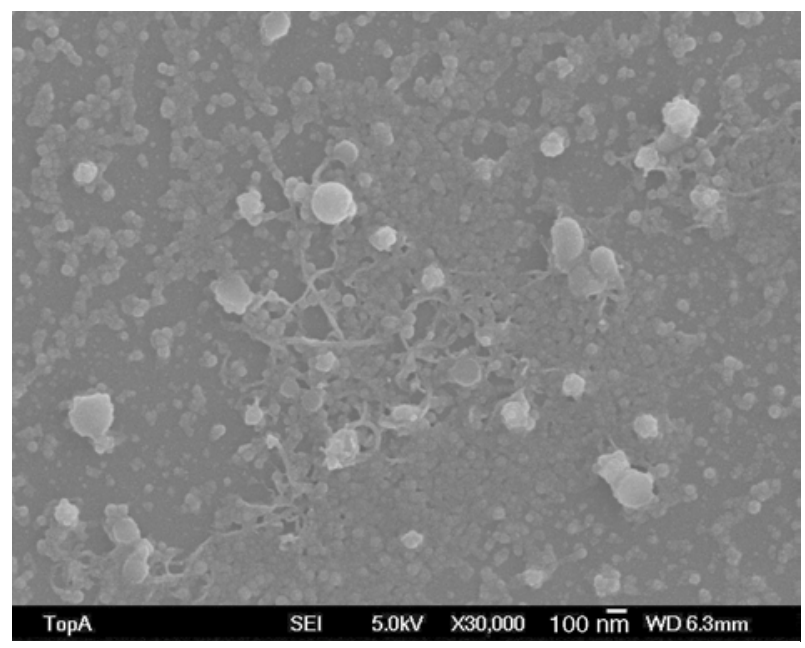

Figure 3. SEM micrograph of dried PS-masterbatch emulsion, AIBN as an initiator in the polymerization weight decreased the viscosity of the masterbatch, but was offset by the presence of CNTs.

An optimum viscosity ratio of the components was achieved when glycerol was added to the low molecular weight PS-masterbatch, with a corresponding decrease in resistivity of the final composite. The viscosity and dynamic moduli of the final composite increased when glycerol was added to the low molecular weight PS-masterbatch (Figure 1). With the addition of glycerol, the plasticized PS-masterbatch formed finer phase morphology in the final composite and the CNTs were able to diffuse into the PS matrix, which slightly increased the viscosity of the final composite. The $T_{\mathrm{g}}$ values of the pure composite components correlated, to some extent, with the viscosities of the composites (Table 2). The PS matrix had the lowest $T_{\mathrm{g}}$, but the high molecular weight PS-masterbatch had a similar value. The low molecular weight PS-masterbatch showed the highest $T_{\mathrm{g}}$. Due to the initiator used in the in situ polymerization of the low molecular weight PS-masterbatch, there were polymer chains grafted to the CNTs, which increased the $T_{\mathrm{g}}$ of the PS-masterbatch.

The matrix polymers were processed similarly as composites, in order to diminish the processing effects on the mechanical properties of CNT composites. The processing itself deteriorated the mechanical properties, which can be seen by comparing the values of pure matrix polymers given by the manufacturers and the values of processed matrix polymers (Tables 1 and 3). Tensile strength and strain at break for PS are 43.0 MPa and 2.0\%, and for PMMA 73.0 $\mathrm{MPa}$ and $11.0 \%$, respectively, given by manufacturers.

Table 3. The electrical resistivity and mechanical properties of PMMA samples

\begin{tabular}{|c|c|c|c|c|c|}
\hline Sample & $\begin{array}{c}\text { CNT content } \\
{[w t \%]}\end{array}$ & $\begin{array}{c}\text { Electrical resistivity } \\
{[\Omega \cdot \mathrm{cm}]}\end{array}$ & $\begin{array}{c}\text { Young's modulus } \\
\text { [MPa] }\end{array}$ & $\begin{array}{c}\text { Tensile strength } \\
{[\mathrm{MPa}]}\end{array}$ & $\begin{array}{c}\text { Strain } \\
{[\%]}\end{array}$ \\
\hline PMMA & - & $>10^{15}$ a) & $1220 \pm 39$ & $58 \pm 3$ & $6.2 \pm 0.5$ \\
\hline $1 \mathrm{CNTs} / \mathrm{PMMA}$ & 1 & $>10^{9}$ & - & - & - \\
\hline $1 \mathrm{MB}_{\mathrm{PMMA}} / \mathrm{PMMA}$ & 1 & $>10^{9}$ & - & - & - \\
\hline 2 CNTs/PMMA & 2 & $>10^{9}$ & $1260 \pm 50$ & $41 \pm 6$ & $3.6 \pm 0.6$ \\
\hline $2 \mathrm{MB}_{\mathrm{PMMA}} / \mathrm{PMMA}$ & 2 & $>10^{9}$ & $1240 \pm 33$ & $25 \pm 4$ & $2.4 \pm 0.4$ \\
\hline 2 MB $_{\text {PMMA }}$ plast30/PMMA & 2 & $1.1 \cdot 10^{8}$ & - & - & - \\
\hline $2 \mathrm{MB}_{\text {PMMA }}$ plast50/PMMA & 2 & $4.1 \cdot 10^{7}$ & - & - & - \\
\hline 3 CNTs/PMMA & 3 & $>10^{9}$ & $1280 \pm 35$ & $32 \pm 10$ & $3.5 \pm 0.8$ \\
\hline $3 \mathrm{MB}_{\mathrm{PMMA}} / \mathrm{PMMA}$ & 3 & $>10^{9}$ & $1270 \pm 10$ & $20 \pm 4$ & $2.1 \pm 0.05$ \\
\hline 3 MBPMMA plast30/PMMA & 3 & 320 & $989 \pm 69$ & $26 \pm 8$ & $3.2 \pm 1.3$ \\
\hline $4 \mathrm{CNTs} / \mathrm{PMMA}$ & 4 & $>10^{9}$ & - & - & - \\
\hline $4 \mathrm{MB}_{\mathrm{PMMA}} / \mathrm{PMMA}$ & 4 & $1.3 \cdot 10^{5}$ & - & - & - \\
\hline
\end{tabular}

a)The resistivity of pure PMMA is a literature value, from [26] 
Compounding CNTs directly with the matrix polymer appeared to slightly weaken the mechanical properties. In the case of PS, tensile modulus was affected more by the high molecular weight PSmasterbatch than by CNTs (Table 1). Tensile modulus was slightly higher when the high molecular weight PS-masterbatch was used. The direct addition of CNTs into the PS matrix did not affect tensile modulus, nor did the use of the low molecular weight PS-masterbatch. The improvement of mechanical properties depending on the molecular weight of the PS-masterbatch was seen more clearly in tensile strength. Tensile strength decreased when CNTs were added directly to PS matrix, which implies that CNTs were agglomerated and not dispersed as individual tubes. It has been observed that the addition of $0.15 \mathrm{wt} \%$ purified CNTs into a polystyrene slightly

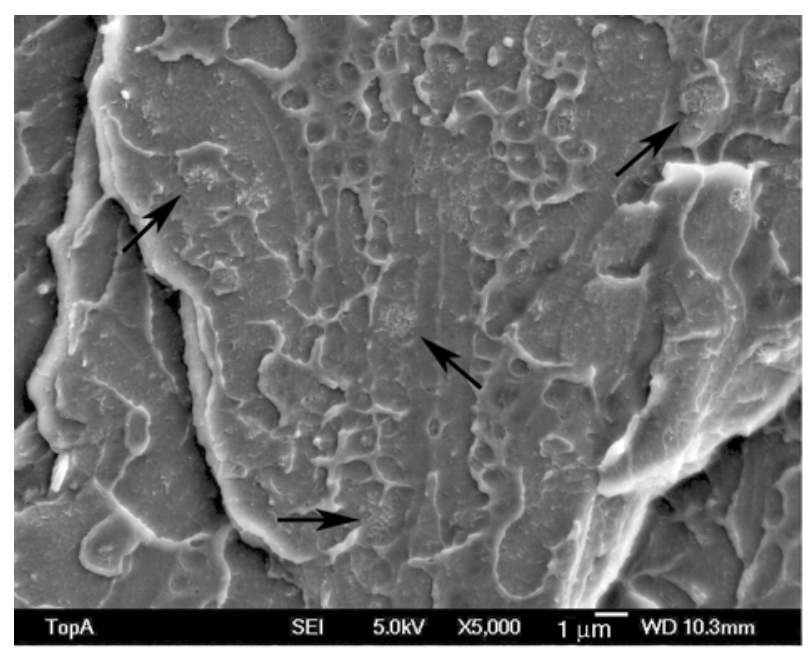

a)

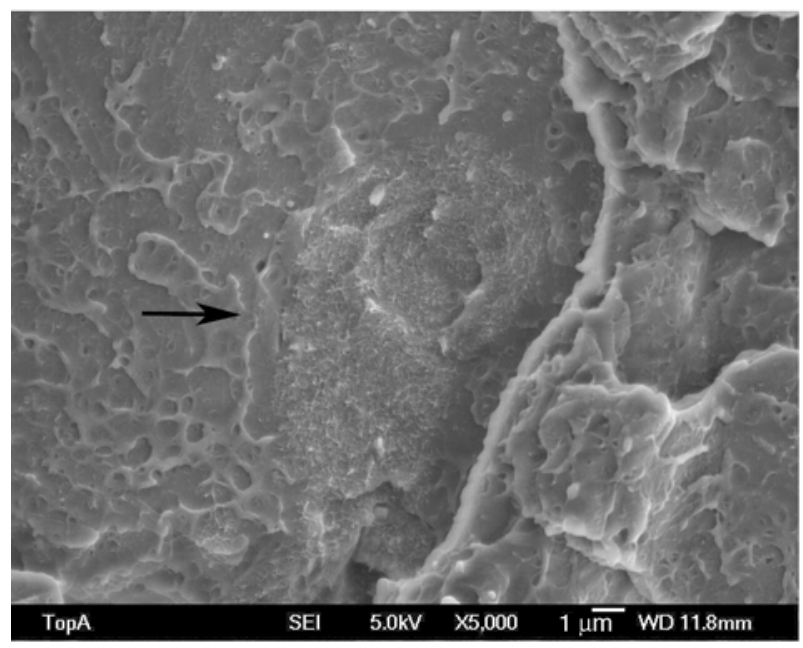

c) decreased tensile strength [22]. When the amount of CNTs increased to $4 \mathrm{wt} \%$, they began to strengthen the composite, as a micro-size filler. The addition of plasticizer to the low molecular weight PS-masterbatch decreased the mechanical properties of the final PS composite (Table 1).

The SEM micrographs confirmed that the CNTs and the masterbatches formed separate phases in the final composites (Figures 4-5). The obtained resistivities of PS composites were ca. $10^{5} \Omega \cdot \mathrm{cm}$. Though $\pi$-stacking between CNTs and PS limits the reagglomeration of CNTs, the CNTs formed agglomerates and behaved as macroscopic particles rather than individual nanoparticles in the directly melt mixed CNT composites. The diameter of CNT agglomerates was ca. $1 \mu \mathrm{m}$ in the PS matrix, and the effect of the agglomerates can be seen in the mechan-

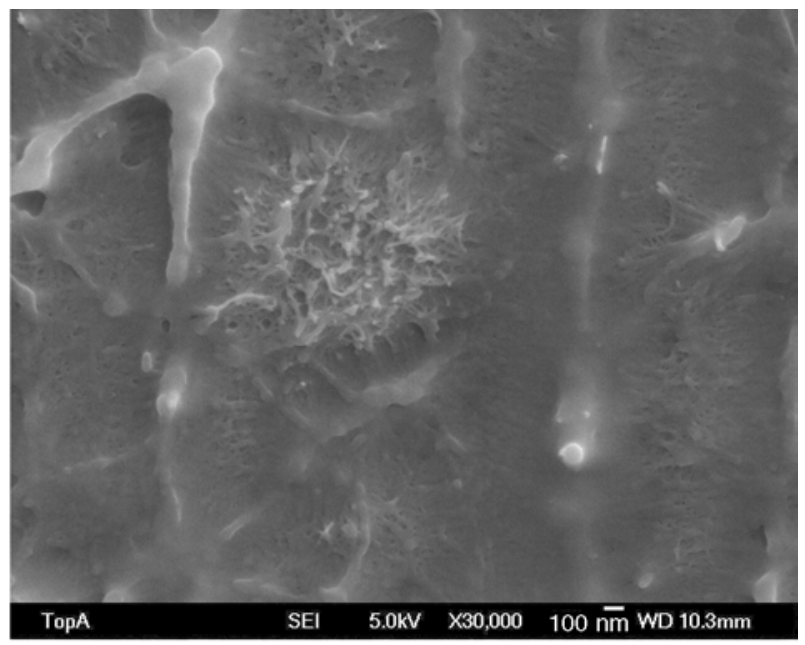

b)

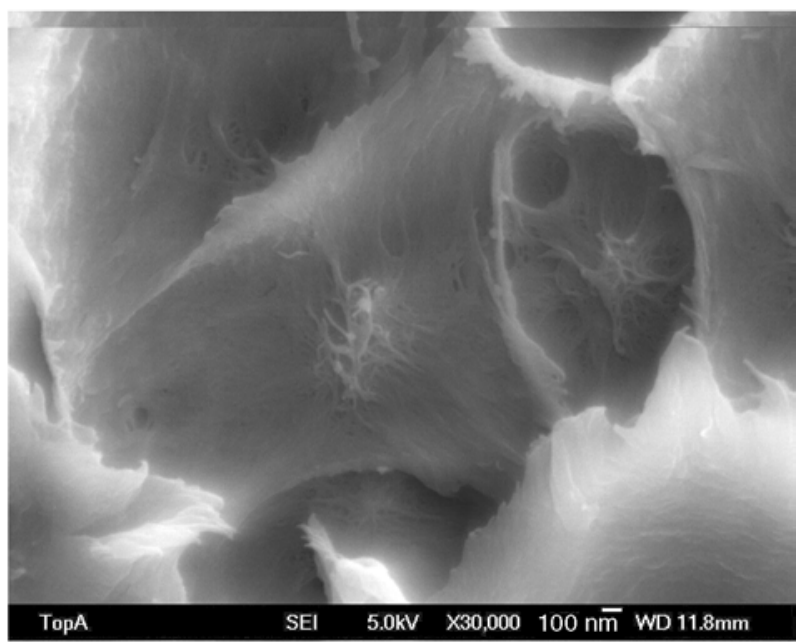

d)

Figure 4. SEM micrographs of fracture surfaces of PS extrudates, a) $2 \mathrm{wt} \%$ CNTs in the final composite, prepared directly melt-mixed CNTs (2 CNTs/PS), b) higher magnification of $2 \mathrm{CNTs} / \mathrm{PS}$ composite c) $2 \mathrm{wt} \% \mathrm{CNTs}$ in the final composite, prepared using masterbatch (2 $\left.\mathrm{MB}_{\mathrm{PS}, \mathrm{AIBN}} / \mathrm{PS}\right)$, and d) higher magnification of $2 \mathrm{MB}_{\mathrm{PS}, \mathrm{AIBN}} / \mathrm{PS}$ composite 


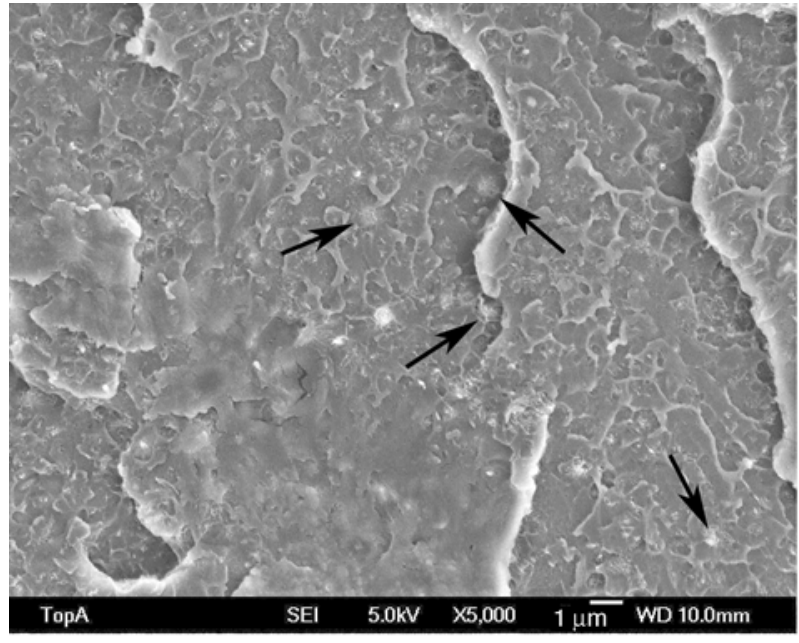

a)

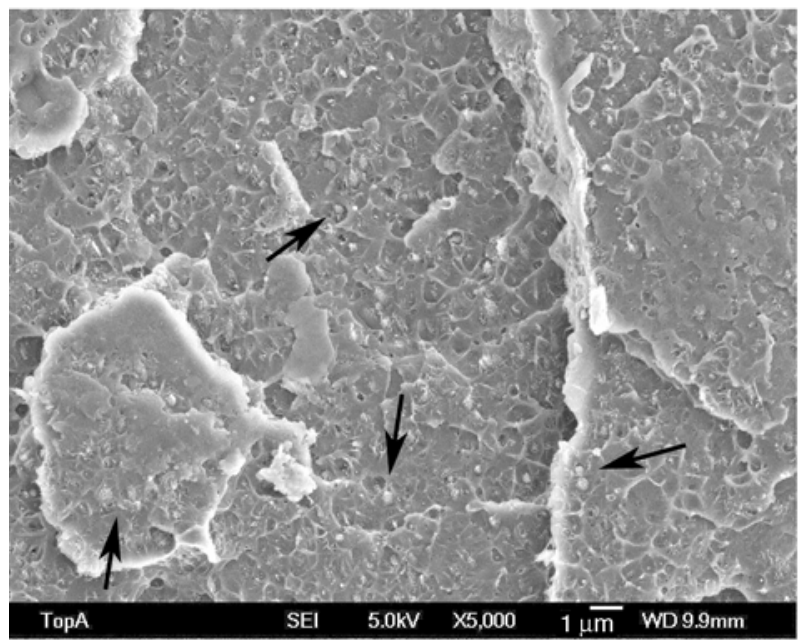

c)

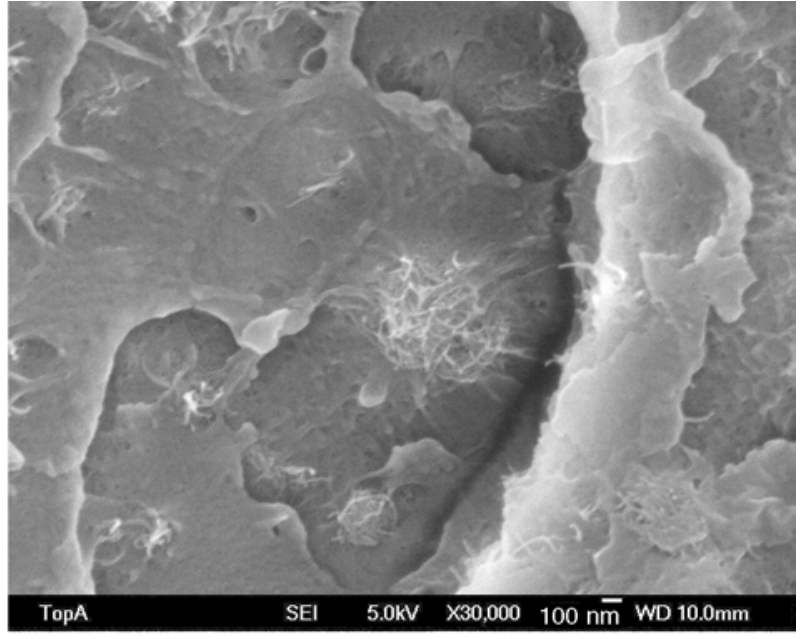

b)

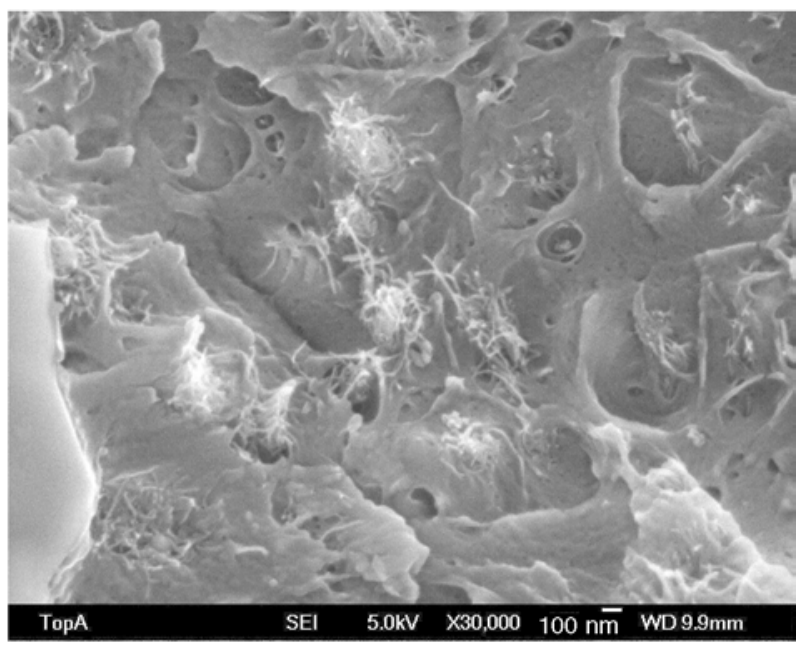

d)

Figure 5. SEM micrographs of fracture surfaces of PMMA extrudates, a) $3 \mathrm{wt} \%$ CNTs in the final composite, prepared directly melt-mixed CNTs (3 CNTs/PMMA), b) higher magnification of 3 CNTs/PMMA composite c) 3 wt $\%$ CNTs in the final composite, prepared using masterbatch ( $\left.3 \mathrm{MB}_{\mathrm{PMMA}} / \mathrm{PMMA}\right)$, and d) higher magnification of $3 \mathrm{MB}_{\mathrm{PMMA}} / \mathrm{PMMA}$ composite

ical properties, which were not improved as much as expected based on the amount of CNTs. On the other hand, CNTs were partly dispersed as individual tubes that formed an agglomerated network which improved the conductivity of the composite. In the final PS composites with PS-masterbatches, CNTs were mainly in the masterbatch phase and they were covered with in situ polymerized styrene (Figure $4 c-d$ ). In the previous study of in situ polymerization of PS-CNT composites, the obtained resistances were under $100 \Omega$ [24]. Even though the resistivity and resistance values are not exactly proportional, the difference between the conductivities of the final PS composites and in situ polymerized PS-CNT composites indicates, in accordance with SEM image (Figure 4c), that the PS-masterbatch was dispersed in the matrix. Therefore, the resistiv- ities of the final composites with PS-masterbatches were relatively high.

In the case of PMMA, without significant interfacial adhesion between the matrix polymer and the CNTs, there are only shear forces in the midiextruder to break up the CNT agglomerates. In addition, there are no additional forces to break up the CNT agglomerates and inhibit the reagglomeration of CNTs. The resistivity values of PS composites were clear indicators to select the efficient mixing parameters for PMMA. When the same mixing parameters were used, directly melt mixed PMMACNT composites were not conductive even with CNT loading of $4 \mathrm{wt} \%$ (Table 3 ).

To form a conductive network of CNTs in the PMMA matrix, the PMMA-masterbatch was tested. The low molecular weight masterbatch was chosen based 
on the results of PS-masterbatches. The use of the PMMA-masterbatch gave clearly lower resistivity values than the use of the directly melt mixed CNTs (Table 3). A conductive composite was achieved below $4 \mathrm{wt} \%$ CNTs when the PMMA-masterbatch was used. When the viscosity of the PMMA-masterbatch was decreased with glycerol, the conductive composite was achieved below $3 \mathrm{wt} \%$ CNTs. Moderately low resistivity was achieved even with $2 \mathrm{wt} \%$ CNTs when a higher amount of glycerol was added to the PMMA-masterbatch.

As the viscosity of the components had an effect on the properties of the PS composites, the PMMA composites was analyzed by rheometry. The rheological behavior of PMMA composites was more straightforward than the case of PS composites (Figure 2). The addition of CNTs increased the viscosity of the PMMA matrix, and viscosity was highest when the PMMA-masterbatch was used. The PMMA-masterbatch had a higher molecular weight than the PMMA matrix and most of the CNTs were located in the PMMA-masterbatch phase, and both these factors led to an increase in viscosity.

When glycerol was added to the PMMA-masterbatch, the viscosity of the final PMMA composite was lower than the directly melt mixed CNT composite with a constant amount of CNTs. The glass transition temperatures, which were measured directly from the masterbatches as well as the matrix polymers, follow the trends in molecular weight and plasticization (Table 2). The PMMA matrix had the lowest $T_{\mathrm{g}}$ and the PMMA-masterbatch with higher molecular weight and CNTs had the highest $T_{\mathrm{g}}$. When the PMMA-masterbatch was plasticized, the $T_{\mathrm{g}}$ shifted to a lower temperature. $T_{\mathrm{g}}$ of the plasticized PS-masterbatch was almost identical to the unplasticized PS-masterbatch. In the case of PMMA, without additional covalent bonds formed by initiators or other interfacial interactions between PMMA and CNTs, the plasticization of the PMMA-masterbatch was more effective than plasticization of the PS-masterbatch. Because of the improved plasticization of PMMA-masterbatch, the viscosity ratio of the components in PMMA composites was optimized, and PMMA-masterbatch formed continuous phase.

Due to the effective plasticization of the PMMAmasterbatch, tensile modulus was mainly affected by the plasticizer and not by the CNTs (Table 3).
Without interactions between PMMA and CNTs, tensile modulus remained at similar values regardless of how CNTs were introduced into the PMMA matrix. On the other hand, tensile strength of the PMMA composites decreased after the addition of CNTs, which was more pronounced with the use of the PMMA-masterbatch than with directly melt mixed CNTs. However, tensile strength of the PMMA composite was improved upon addition of plasticizer to the PMMA-masterbatch. The same behavior can be seen for tensile strain at break. This may be taken as indirect evidence that CNTs were well-dispersed in the plasticized PMMA composite. Based on the SEM images, CNTs agglomerates were larger in the PS composites compared to the PMMA composites (Figures 4-5). The diameter of CNT agglomerates was ca. $0.5 \mu \mathrm{m}$ in the PMMA matrix (Figure 5), which was half of the diameter of the CNT agglomerates in the PS matrix. Though the CNTs formed smaller agglomerates in the PMMA matrix, the resistivity of the PMMA composites was high. CNTs were mostly present in the form of agglomerates without individualized CNTs forming a network which would increase conductivity into the composites. Contrary to the PS composites, the PMMA-masterbatch formed a continuous phase in the final PMMA composite. In the previous study of in situ polymerization of CNT/PMMA composite, the obtained resistances were ca. $100 \Omega$ [24], which are similar to the resistivities of PMMA-masterbatch composites, $100 \Omega \cdot \mathrm{cm}$. This indicates that there was the continuous phase of PMMA-masterbatch in the final PMMA composite. Finer phase morphology of PMMA-masterbatch in the PMMA matrix can be seen in the SEM image (Figure 5c) compared to the PS-masterbatch in the PS composite (Figure 4c). The CNTs were not coated by polymerized methyl methacrylate in the PMMA-masterbatch, and CNTs can diffuse more easily during melt mixing. Therefore, the use of PMMA-masterbatch improved the conductivity of the final composites of PMMA.

\section{Conclusions}

The properties of composite materials are determined by many different variables. It is not the sum of the mechanical and electrical properties of the components that determines properties of the final composite. The rheological properties of the materi- 
als and the internal and external forces, such as interfacial interactions between the components and mechanical mixing forces, have great impact on the properties of the composite. Two different CNT composites were studied: PS composites with interactions between the components and PMMA composites without interactions between the components. The results confirm that, for lowering the percolation threshold of CNTs, novel compounding methods are needed, as there are limited possibilities for adjusting the shear forces during melt mixing. The mechanical properties of the composites were mostly determined by the amount of CNTs. In contrast, the resistivity of the composites was more dependent on how CNTs were added into the matrix polymer. In the case of PS composites with stronger interfacial interactions between the components, CNTs can be directly melt mixed into the PS matrix and obtain a conductive composite. The strong interaction between CNTs and PS enhanced the dispersion of the CNTs. But without significant adhesion between the components, the use of a masterbatch improved the conductivity of PMMA composites. In the case of PMMA, there are no strong interactions between CNTs and the matrix during melt mixing, and there was only small amount of individually dispersed CNTs in the PMMA matrix. Due to the ease of emulsion polymerization of the masterbatch, the properties of the masterbatch could be tailored based on the molecular weight and viscosity, thereby tailoring the properties of the final composite. When CNTs were well-dispersed in a PMMAmasterbatch, which had optimized viscosity compared to the PMMA matrix, the use of a PMMAmasterbatch notably decreased the percolation threshold of the CNT-PMMA composite.

\section{Acknowledgements}

The Finnish Funding Agency for Technology and Innovation (Tekes, project 2330/31/06) and POPROK Graduate School are thanked for financial support. Mr. Antti Metsälä is warmly thanked.

\section{References}

[1] Gorga R. E., Cohen R. E.: Toughness enhancements in poly(methyl methacrylate) by addition of oriented multiwall carbon nanotubes. Journal of Polymer Science Part B: Polymer Physics, 42, 2690-2702 (2004). DOI: $10.1002 /$ polb.20126
[2] Feldman A. Y., Larin B., Berestetsky N., Marom G., Weinberg A.: Microbeam WAXD study of orientated crystalline arrays in carbon fiber/CNT - nylon 66 extruded/drawn composites. Journal of Macromolecular Science Part B: Physics, 46, 111-117 (2007). DOI: $10.1080 / 00222340601044243$

[3] Salalha W., Dror Y., Khalfin R. L., Cohen Y., Yarin A. L., Zussman E.: Single-walled carbon nanotubes embedded in oriented polymeric nanofibers by electrospinning. Langmuir, 20, 9852-9855 (2004).

DOI: $10.1021 / 1 \mathrm{a} 048536 \mathrm{~b}$

[4] Du F., Fischer J. E., Winey K. I.: Coagulation method for preparing single-walled carbon nanotube/poly (methyl methacrylate) composites and their modulus, electrical conductivity, and thermal stability. Journal of Polymer Science Part B: Polymer Physics, 41, 3333-3338 (2003).

DOI: $10.1002 /$ polb.10701

[5] Kharchenko S. B., Douglas J. F., Obrzut J., Grulke E. A., Migler K. B.: Flow-induced properties of nanotube-filled polymer materials. Nature Materials, 3, 564-568 (2004).

DOI: $10.1038 / \mathrm{nmat} 1183$

[6] Mičušík M., Omastová M., Krupa I., Prokeš J., Pissis P., Logakis E., Pandis C., Pötschke P., Pionteck J.: A comparative study on the electrical and mechanical behaviour of multi-walled carbon nanotube composites prepared by diluting a masterbatch with various types of polypropylenes. Journal of Applied Polymer Science, 113, 2536-2551 (2009).

DOI: 10.1002/app.30418

[7] Moniruzzaman M., Winey K. I.: Polymer nanocomposites containing carbon nanotubes. Macromolecules, 39, 5194-5205 (2006).

DOI: $10.1021 / \mathrm{ma} 060733 p$

[8] Jin S. H., Kang C. H., Yoon K. H., Bang D. S., Park YB.: Effect of compatibilizer on morphology, thermal, and rheological properties of polypropylene/functionalized multi-walled carbon nanotubes composite. Journal of Applied Polymer Science, 111, 1028-1033 (2009).

DOI: $10.1002 /$ app.29009

[9] Lin B., Sundararaj U., Pötschke P.: Melt mixing of polycarbonate with multi-walled carbon nanotubes in miniature mixers. Macromolecular Materials and Engineering, 291, 227-238 (2006). DOI: $10.1002 /$ mame.200500335

[10] Isayev A. I., Kumar R., Lewis T. M.: Ultrasound assisted twin screw extrusion of polymer-nanocomposites containing carbon nanotubes. Polymer, 50, 250260 (2009). DOI: $10.1016 /$ j.polymer.2008.10.052

[11] Coleman J. N., Cadek M., Ryan K. P., Fonseca A., Nagy J. B., Blau W. J., Ferreira M. S.: Reinforcement of polymers with carbon nanotubes. The role of an ordered polymer interfacial region. Experiment and modeling. Polymer, 47, 8556-8561 (2006). DOI: $10.1016 /$ j.polymer.2006.10.014 
[12] Wiemann K., Kaminsky W., Gojny F. H., Schulte K.: Synthesis and properties of syndiotactic poly(propylene)/carbon nanofiber and nanotube composites prepared by in situ polymerization with metallocene/ MAO catalysts. Macromolecular Chemistry and Physics, 206, 1472-1478 (2005).

DOI: $10.1002 /$ macp. 200500066

[13] Zhou Z., Wang S., Zhang Y., Zhang Y.: Effect of different carbon fillers on the properties of PP composites: Comparison of carbon black with multiwalled carbon nanotubes. Journal of Applied Polymer Science, 102, 4823-4830 (2006).

DOI: 10.1002/app.24722

[14] Logakis E., Pandis C., Peoglos V., Pissis P., Stergiou C., Pionteck J., Pötschke P., Mičušík M., Omastová M.: Structure-property relationships in polyamide 6/ multi-walled carbon nanotubes nanocomposites. Journal of Polymer Science Part B: Polymer Physics, 47, 764-774 (2009).

DOI: $10.1002 /$ polb.21681

[15] Zhao C., Hu G., Justice R., Schaefer D. W., Zhang S., Yang M., Han C. C.: Synthesis and characterization of multi-walled carbon nanotubes reinforced polyamide 6 via in situ polymerization. Polymer, 46, 5125-5132 (2005).

DOI: 10.1016/j.polymer.2005.04.065

[16] Jordhamo G. M., Manson J. A., Sperling L. H.: Phase continuity and inversion in polymer blends and simultaneous interpenetrating networks. Polymer Engineering and Science, 26, 517-524 (1986).

DOI: $10.1002 /$ pen.760260802

[17] Ports B. F., Weiss R. A.: One-step melt extrusion process for preparing polyolefin/clay nanocomposites using natural montmorillonite. Industrial and Engineering Chemistry Research, 49, 11896-11905 (2010). DOI: 10.1021/ie902050r

[18] Meincke O., Kaempfer D., Weickmann H., Friedrich C., Vathauer M., Warth H.: Mechanical properties and electrical conductivity of carbon-nanotube filled polyamide- 6 and its blends with acrylonitrile/butadiene/ styrene. Polymer, 45, 739-748 (2004).

DOI: $10.1016 /$ j.polymer.2003.12.013

[19] Pötschke P., Bhattacharyya A. R., Janke A.: Morphology and electrical resistivity of melt mixed blends of polyethylene and carbon nanotube filled polycarbonate. Polymer, 44, 8061-8069 (2003).

DOI: $10.1016 /$ j.polymer.2003.10.003
[20] Grossiord N., Kivit P. J. J., Loos J., Meuldijk J., Kyrylyuk A. V., van der Schoot P., Koning C. E.: On the influence of the processing conditions on the performance of electrically conductive carbon nanotube/polymer nanocomposites. Polymer, 49, 2866-2872 (2008). DOI: $10.1016 /$ j.polymer.2008.04.033

[21] Pötschke P., Pegel S., Claes M., Bonduel D.: A novel strategy to incorporate carbon nanotubes into thermoplastic matrices. Macromolecular Rapid Communications, 29, 244-251 (2008).

DOI: $10.1002 /$ marc. 200700637

[22] Yuan J-M., Fan Z-F., Chen X-H., Chen X-H., Wu Z-J., He L-P.: Preparation of polystyrene-multiwalled carbon nanotube composites with individual-dispersed nanotubes and strong interfacial adhesion. Polymer, 50, 3285-3291 (2009).

DOI: $10.1016 /$ j.polymer.2009.04.065

[23] Tong X., Liu C., Cheng H-M., Zhao H., Yang F., Zhang X.: Surface modification of single-walled carbon nanotubes with polyethylene via in situ ZieglerNatta polymerization. Journal of Applied Polymer Science, 92, 3697-3700 (2004).

DOI: 10.1002 app.20306

[24] Lahelin M., Annala M., Nykänen A., Ruokolainen J., Seppälä J.: In situ polymerized nanocomposites: Polystyrene/CNT and poly(methyl methacrylate)/CNT composites. Composites Science and Technology, 71, 900-907 (2011).

DOI: 10.1016/j.compscitech.2011.02.005

[25] Schrader D.: Physical constants of poly(styrene). in 'Polymer handbook' (eds.: Brandrup J., Immergut E. H., Grulke E. A., Abe A., Bloch D. R.) Wiley, New York, V/91-V/96 (1999).

[26] Wunderlich W.: Physical constants of poly(methyl methacrylate), in 'Polymer handbook' (eds.: Brandrup J., Immergut E. H., Grulke E. A., Abe A., Bloch D. R.) Wiley, New York, V/87-V/90 (1999).

[27] Jia Z., Wang Z., Xu C., Liang J., Wei B., Wu D., Zhu S.: Study on poly(methyl methacrylate)/carbon nanotube composites. Materials Science and Engineering A, 271, 395-400 (1999). DOI: 10.1016/S0921-5093(99)00263-4 